\title{
Apex two dimensional echocardiography Alternative approach to quantification of acute myocardial infarction
}

\author{
C A VISSER, G KAN, K I LIE, A E BECKER, D DURRER \\ From the Departments of Cardiology and Clinical Physiology and Pathology, and the Interuniversity Cardiology \\ Institute, University of Amsterdam, Wilhelmina Gasthuis, Amsterdam, The Netherlands
}

SUMMARY Apex echocardiography has been chosen as an approach to detect and quantify acute myocardial infarction because the usual parasternal acoustic windows are often occluded. Fifty-three patients were studied, all within 12 hours after the onset of symptoms of their first myocardial infarction. Three apical long axis views were obtained, that is the two and four chamber views; and the right anterior oblique equivalent or three chamber view. Satisfactory echocardiograms were obtained in 48 patients (91\%). The individual apical views were divided into equal segments and the area of asynergy was estimated in each view.

Left ventricular asynergy was present in all 48 patients. In 46 patients a positive correlation between the electrocardiogram and the echocardiogram was obtained, as far as infarct localisation was concerned. The estimated asynergic area correlated well with the peak value of the isoenzyme of creatine kinase (CK MB).

Apex echocardiography is a reliable alternative method of detecting and quantifying myocardial infarction soon after the onset of symptoms.

The immediate and long term prognosis of patients with an acute myocardial infarction depends largely on the site and extent of the infarcted myocardium..$^{1-3}$ It is of clinical significance, therefore, to be able to obtain reliable data regarding these features early after the onset of symptoms.

Various non-invasive techniques to determine infarct size have been developed recently, ${ }^{4-6}$ of which echocardiography appears particularly useful since it can be performed at the bedside, involves no risk for the patient, is reproducible, and is capable of visualising the entire left ventricular wall. ${ }^{7}$ In animal ${ }^{8-10}$ and human ${ }^{11-13}$ studies the regional wall motion abnormalities that occur with myocardial infarction have been visualised on two dimensional echocardiography and used to quantify the necrotic area. The success rate of obtaining adequate echocardiographic results in patients with an acute myocardial infarction, however, is limited ${ }^{11} 14$ since the parasternal acoustic windows are often closed because of chronic lung disease.

It is for this reason that we used the site of the cardiac apex for the two dimensional echocardioAccepted for publication 7 January 1982 graphic localisation and quantification of regional wall motion abnormalities in patients with an acute myocardial infarction.

\section{Subjects and methods}

Fifty-three consecutive patients (45 men; eight women) with a first myocardial infarction were studied. Their average age was 57 years (range 36 to 82). Acute myocardial infarction was documented by a typical clinical history, diagnostic $Q$ waves on the electrocardiogram, and elevation of the isoenzyme of creatine kinase (CK MB).

Echocardiographic examination was performed in all patients within 12 hours after the onset of symptoms. Serial CK MB determinations were performed on admission and repeated every four hours thereafter until the peak value was reached. ${ }^{15} \mathrm{~A}$ routine 12 lead electrocardiogram was obtained on admission and repeated every 12 hours during the first three days in hospital. The electrocardiographic infarct. localisation was determined according to the criteria of the New York Heart Association. ${ }^{16}$ 
TWO DIMENSIONAL ECHOCARDIOGRAPHY

All echocardiographic studies were performed using a commercial mechanical sector scanner (Eko-Sector 1, Smith Kline Instruments) with an $82^{\circ}$ sector arc and a $2.25 \mathrm{MHz}$ transducer. The images obtained were stored on videotape for analysis by two observers.

All patients were studied in the left lateral decubitus position. The transducer was placed at the point of maximal impulse of the cardiac apex and the sector was directed towards the left atrium (Fig. 1). The apical four chamber view was first obtained showing the inlet part of the ventricular septum together with the apex and posterolateral wall of the left ventricle. ${ }^{17-19}$ By rotating the transducer approximately 60 degrees clockwise a three chamber view was obtained comparable with the right anterior oblique equivalent. This view shows the outlet part of the ventricular septum, the apex, and the posterior wall of the left ventricle. A two chamber view was obtained by rotating the transducer approximately 60 degrees counterclockwise. This view shows the anterolateral and inferior wall of the left ventricle and the apex. ${ }^{20}$
ECHOCARDIOGRAPHIC ANALYSIS

Left ventricular wall motion of each study was anal- $c$. ysed for the presence and extent of asynergy by two $\Rightarrow$ investigators who had no prior knowledge of the clini- क्? cal status of the patient. The results were compared and occasional discrepancies were resolved by consensus. Precomparison interobserver variation for extent of asynergy was low $(r=0.95)$. Asynergy was defined $\mathbb{\complement}$ as hypokinesia, akinesia, or dyskinesia, as judged by the overall visual impression after reviewing each $\vec{\circ}$ study in real time, slow motion, and stop frame formats.

Asynergy was termed "anterior" if it occurred in the apical, septal, or anterolateral regions and "inferior" if it occurred in the posterior, posterolat- $\exists$ eral, or inferior regions of the left ventricle. The basic ir principles used to estimate infarct size are shown $\vec{\sigma}$ schematically in Fig. 2. Each apical long axis view was divided into equal segments, and the estimated 윽 asynergic area was expressed as a percentage of the total number of segments.
4C

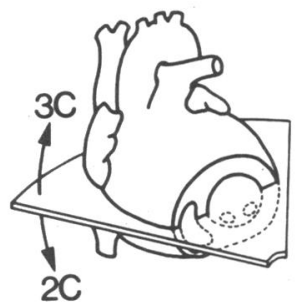

2C

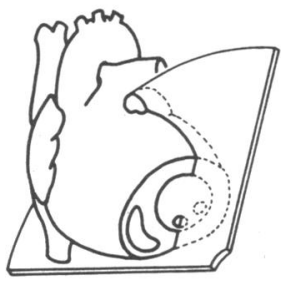

$3 \mathrm{C}$

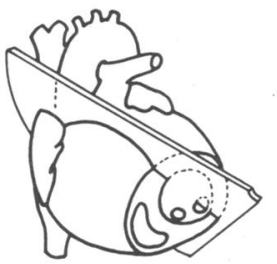

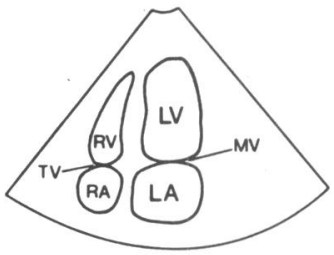
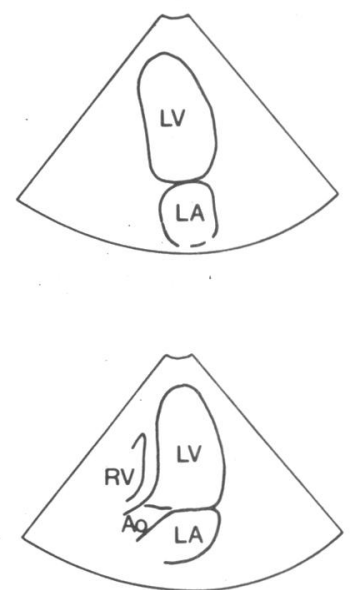
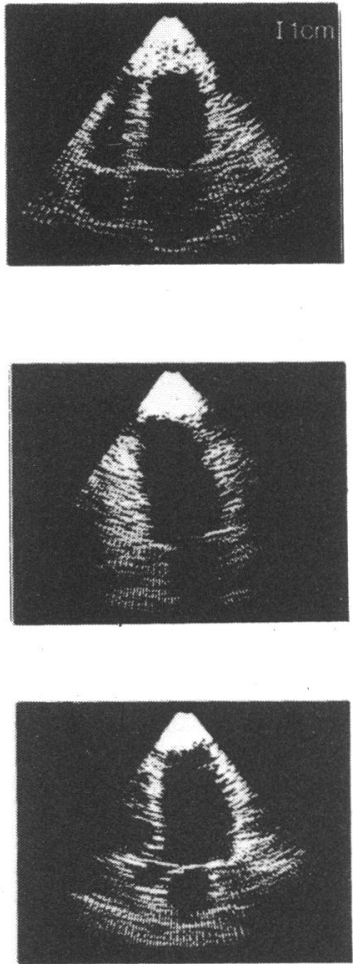

Fig. 1 Diagrams of the three different planes of transsection, together with corresponding stop frames. Ao, aorta; LA, left atrium; $L V$, left ventricle; $M V$, mitral valve; $R V$, right ventricle; $T V$, tricuspid valve; $4 C$, four chamber view; $2 C$, two chamber view; $3 C$, three chamber view. 
2C

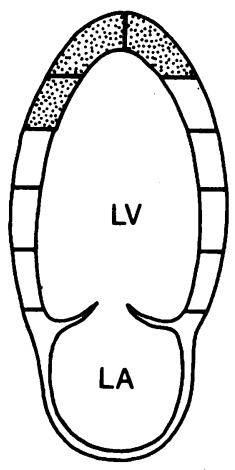

3C

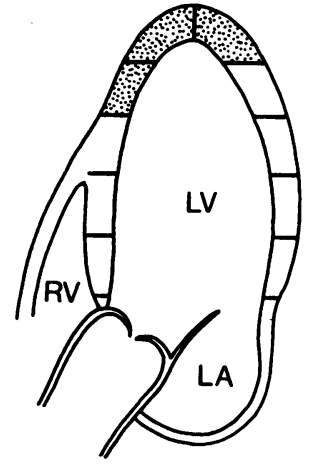

$4 C$

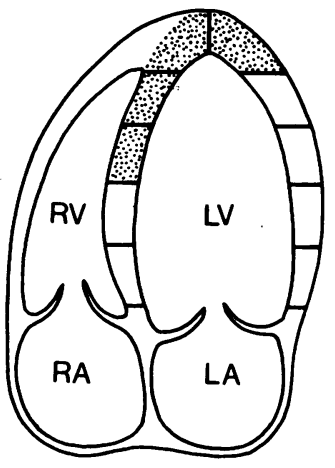

Fig. 2 Schematic diagram showing the three apical long axis views. The lefi ventricular free wall and septum is divided into equal segments. The asynergic area $(A A)$ of the left ventricular wall (dotted segments) is expressed as a percentage of the total number of segments (30). In this example a total infarct size of $33 \%$ is obtained. Abbreviations as in Fig. 1 .

$$
A A=\frac{10}{30} \times 100=33 \%
$$

A
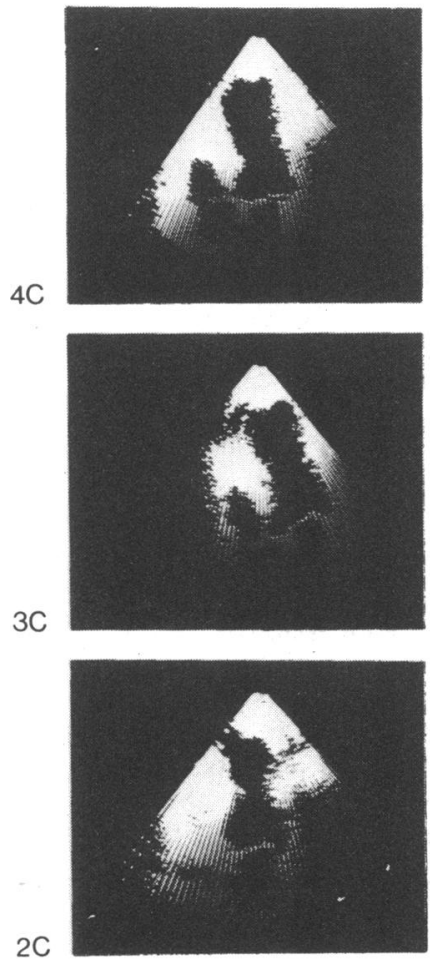

B
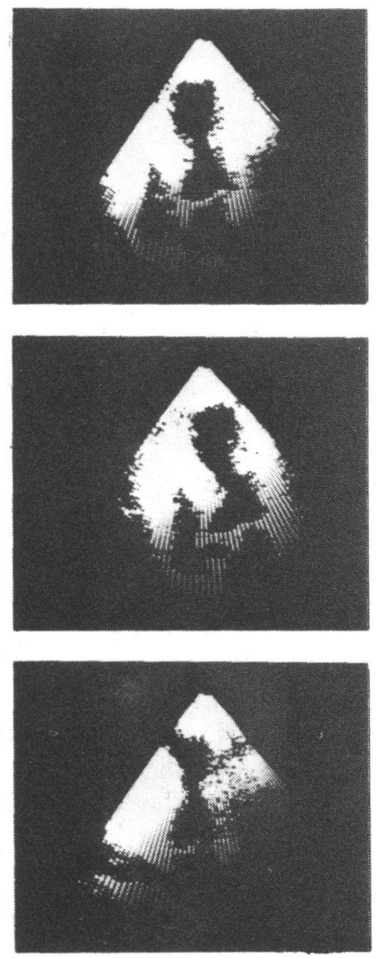

nr 21
C
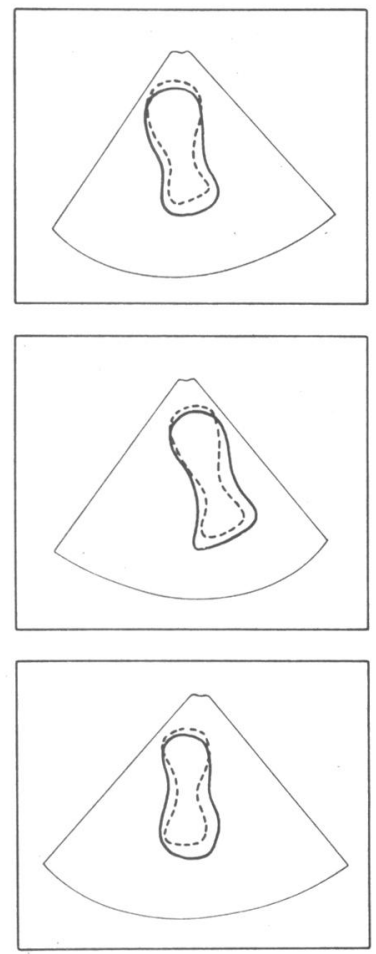

$A A=\frac{11}{30} \times 100=37 \%$
D
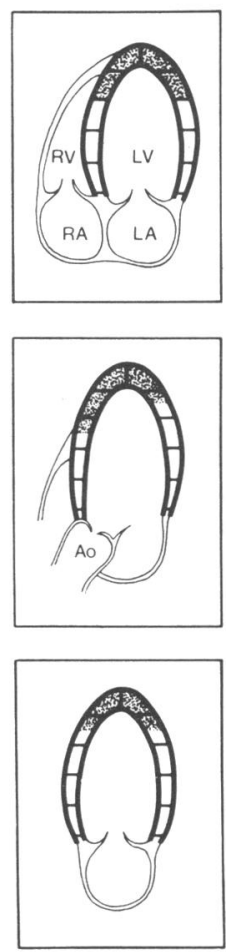

Fig. 3 The panels $A$ and $B$ show the end-diastolic and end-systolic stop frames of each of the three long axis apical views in a patient with an acute anterior infarction, eight hours after onset of symptoms. Panel $C$ shows the diastolic (solid line) and systolic (dotted line) outlines of the left ventricle. There is extensive asynergy. Note also the abmormal diastolic configuration of the left ventricle. In panel $D$ the dotted segments represent the visually estimated asynergic area $(A A)$ of the left ventricular wall, calculated at $37 \%$. Abbreviations as in Fig. 1 . 


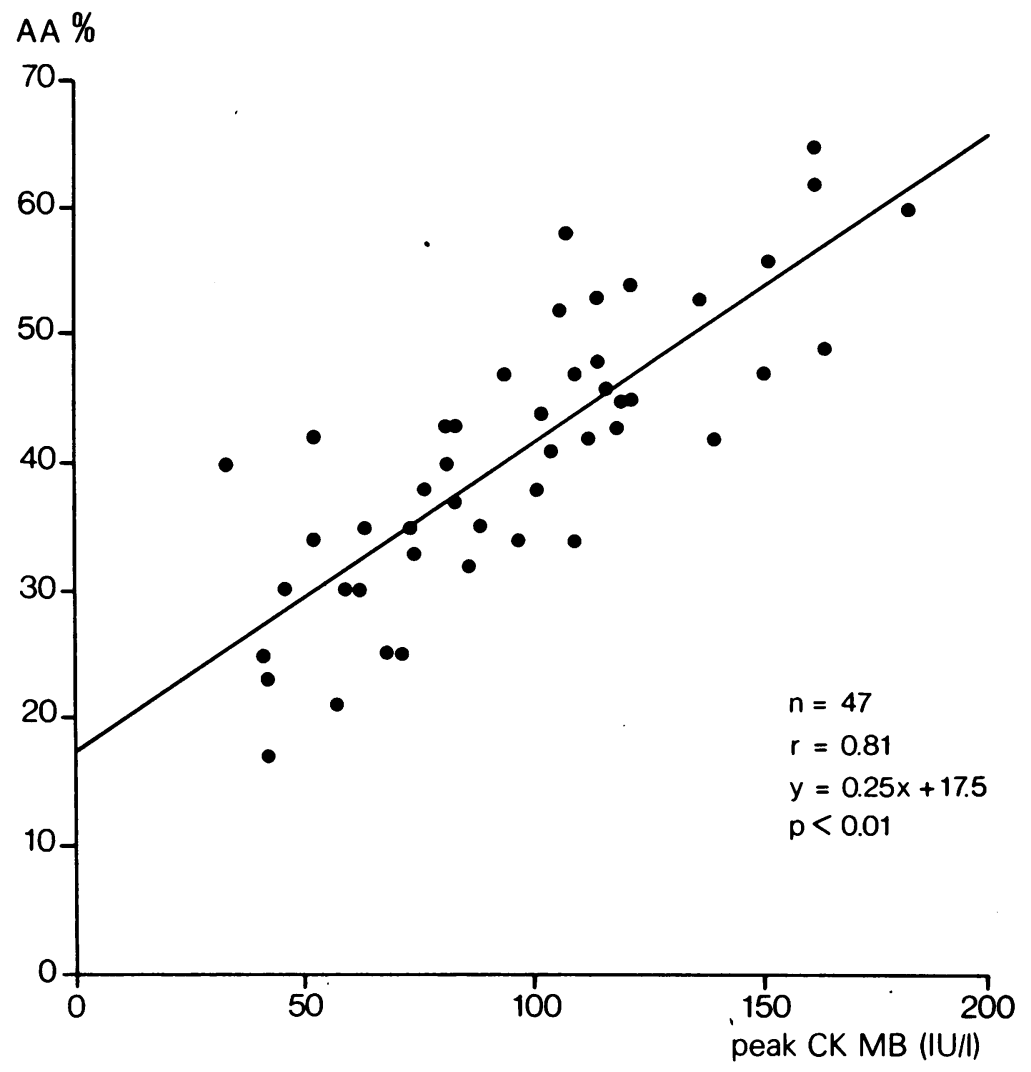

Fig. 4 Diagram of the correlation between the peak value of $C K M B$ and the echocardiographically estimated infarct size (AA). Abbreviation as in Fig. 2.

\section{Results}

In $48(91 \%)$ of the 53 patients ( 40 men; eight women) a complete and adequate two dimensional echocardiographic study was obtained (Fig. 3). Left ventricular asynergy was present in each of the 48 patients.

The unsatisfactory results in the five patients were caused by the left lung overlying the anterolateral left ventricular wall in the two chamber view.

\section{LOCALISATION OF MYOCARDIAL INFARCT}

The electrocardiographic site of infarction was anterior in 24 patients, inferior in 18, and anteroinferior in six patients. The echocardiographic site of infarction was the same in $\mathbf{4 6}$ of the $\mathbf{4 8}$ patients.

Discrepancy between the electrocardiogram and echocardiogram was present in two patients. One patient had an isolated inferior wall infarction on the electrocardiogram while the echocardiogram disclosed additional involvement of the ventricular septum.
The other patient had an isolated anterior wall infarction on the electrocardiogram, but the echocardiogram showed asynergy of the apico-septal wall as well as asynergy of the posterior wall.

\section{QUANTIFICATION OF INFARCT SIZE}

Using the three cross-sections, infarct sizes could be quantified in each of the $\mathbf{4 8}$ patients. A correlation $N$ with the peak CK MB could be obtained in 47 N patients, since one patient died within 18 hours after onset of symptoms. The correlation between both variables is shown in Fig. 4.

\section{POST-MORTEM CORRELATION}

During the period of this study only one patient died. This patient had extensive asynergy of the apical, septal, and anterolateral wall on the echocardiogram. The diastolic configuration, moreover, showed a distinct $\frac{\Omega}{\square}$ outward bulging of the affected area (Fig. 5A).

Necropsy showed an extensive transmural 

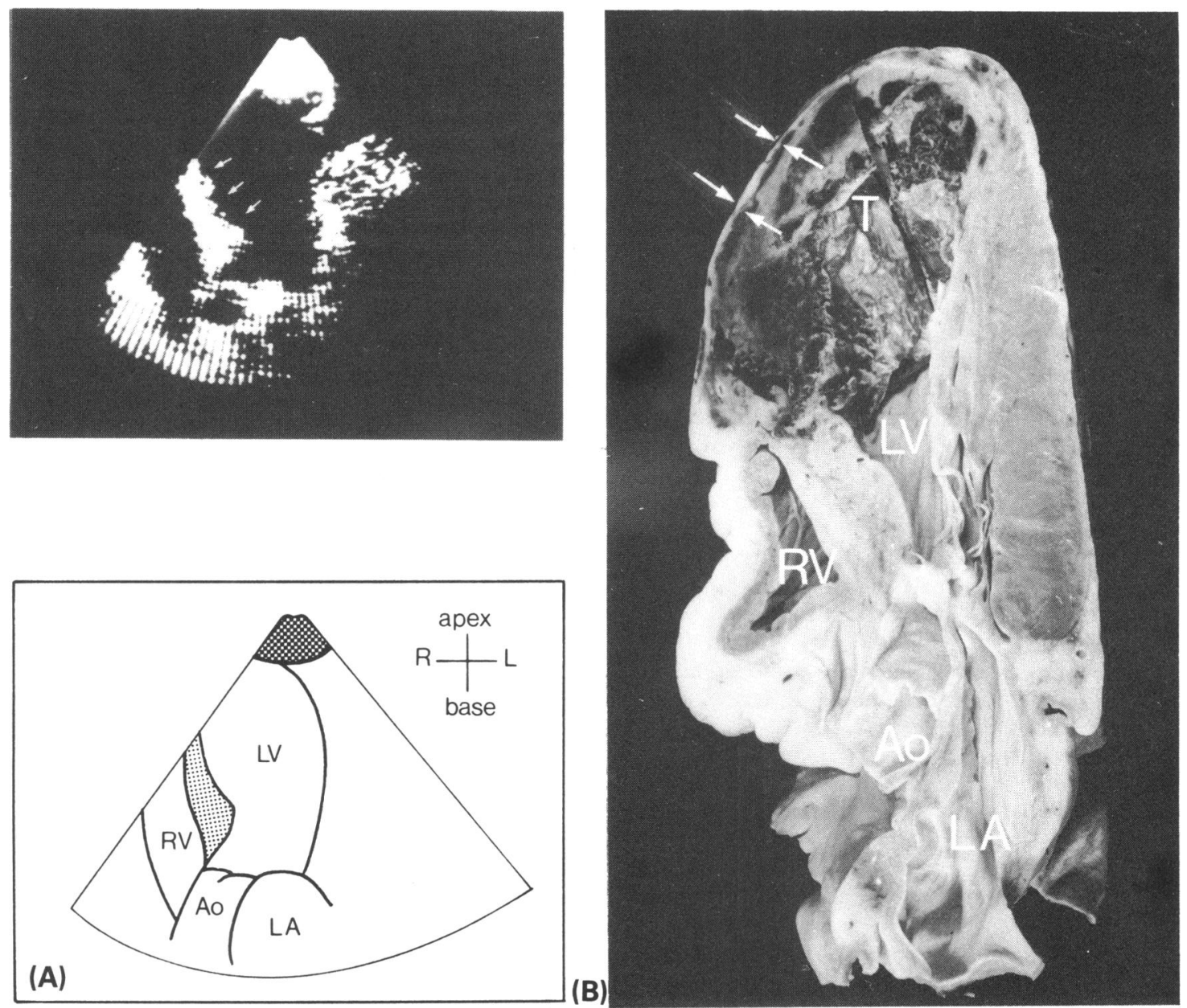

(A)

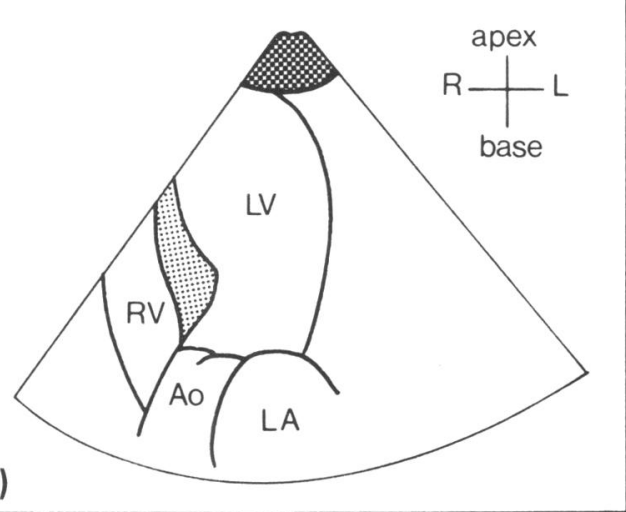

(B)

detecting wall motion abnormalities in patients with an acute myocardial infarction..$^{21-23}$ Unfortunately, the parasternal acoustic windows are often occluded in patients with coronary artery disease because of accompanying pulmonary disease. On the other hand, the site of the cardiac apex is of ten readily amenable to ulcrasound penetration. In many patients with myocardial infarcts, particularly those with anterior wall infarction, the apex of the left ventricle is also involved ${ }^{24} 25$ and, hence, because of apical dilatation, contributes to the size of this acoustic window. With this approach adequate echocardiographic images were obtained in $91 \%$ of the patients. This percentage

Echocardiography is accepted as a reliable method of 
is in accordance with that of reports in which apical long axis views were applied to determine left ventricular volumes, 202627 but is better than the figures reported when only parasternal acoustic windows were used. ${ }^{11} 14$

CORRELATION BETWEEN SITE OF ASYNERGY AND ELECTROCARDIOGRAM

The abnormalities in wall motion were almost totally restricted to the region that correlated with the electrocardiographic infarct site. This finding can be explained by patient selection, since all of the patients were having their first myocardial infarction. A discrepancy was present in only two of the 48 patients. The electrocardiogram of one of these showed an isolated inferior infarction, whereas the echocardiogram disclosed additional asynergy of the adjacent septum. There is still uncertainty as to whether or not the septum was truly infarcted.

Clinical and experimental studies have shown that segments of the left ventricle adjacent to a region of infarction may exhibit asynergy and yet be normal morphologically. ${ }^{28-30}$ On the other hand, inferior infarction may well extend into the interventricular septum without producing characteristic electrocardiographic changes. ${ }^{25} 31$

The echocardiogram of the second patient disclosed asynergy of the apex and septum, in keeping with the electrocardiogram, but in addition showed asynergy of a non-adjacent segment of the posterior wall. The posterior area of the left ventricle is difficult to evaluate electrocardiographically ${ }^{32}$ and this may explain the discrepancy.

\section{QUANTIFICATION OF INFARCT AREA}

As previously outlined, we have taken asynergy as an indicator for myocardial infarction, though we realise that this is not necessarily always the case. At present, however, in judging infarct size this particular feature is the most reliable echocardiographic variable. We showed a linear correlation between infarct size judged from the echocardiograms and that based on the peak values of $\mathrm{CK} M B$, indicating the reliability of the method employed. This conclusion is in keeping with the observation that wall motion abnormality correlates with enzymatic estimates of infarct size. ${ }^{33}$

It is important, furthermore, that the three crosssections do not cover all of the ventricular wall. Despite this restriction, asynergy was encountered in all patients. This could be explained by the fact that the lowest value of the peak $\mathrm{CK} M \mathrm{MB}$ in our population was $33 \mathrm{IU} / 1$ (normal: $4 \mathrm{IU} / 1$ or less), so that the infarcts were probably all sufficiently large to be encountered in at least one of the echocardiographic sections. The asynergic area in 47 patients ranged from 17 to $66 \%$. Some of these values are likely to be exaggerated since a true loss of myocardium of more than $\mathbf{4 0 \%}$ is usually fatal. ${ }^{1}$ Moreover, it is well known from experimental and clinical studies that abnormalities in wall motion extend beyond the region of actual infarction..$^{134} \mathrm{It}$ is of interest, in this regard, that the only patient in this study who died had an estimated infarct size on echocardiographic grounds of approximately $55 \%$, while the necropsy disclosed an infarct of approximately $45 \%$.

From a practical point of view it thus appears that the usual percentages of myocardial loss quoted to predict prognosis, which are all related to the total left ventricular myocardial mass, need an adjustment when based on this particular echocardiographic approach. In our hands this alternative method provides a reliable option in the quantification of infarct size.

\section{References}

1 Page DL, Caulfield JB, Kastor JA, De Sanctis RW, Sanders CA. Myocardial changes associated with cardiogenic shock. N Engl F Med 1971; 285: 133-7.

2 Wolk MJ, Scheidt S, Killip T. Heart failure complicating acute myocardial infarction. Circulation 1972; 45: 1125-38.

3 Harnarayan C, Bennett MA, Pentecost BL, Brewer DB. Quantitative study of infarcted myocardium in cardiogenic shock. Br Heart f 1970; 32: 728-32.

4 Muller JE, Maroko PR, Braunwald E. Precordial electrocardiographic mapping: a technique to assess the efficacy of interventions designed to limit infarct size. Circulation 1978; 57: 1-18.

5 Roberts R, Henry PD, Sobel BE. An improved basis for enzymatic estimation of infarct size. Circulation 1975; 52: 743-54.

6 Wackers FJT, Becker AE, Samson G, et al. Location and size of acute transmural myocardial infarction estimated from thallium-201 scintiscans. Circulation 1977; 56: 72-8.

7 Kisslo JA, Von Ramm OT, Thurstone FL. Cardiac imaging using a phased array ultrasound system. II. Clinical technique and application. Circulation 1976; 53: 262-7.

8 Weyman AE, Franklin TD, Egenes KM, Green D. Correlation between extent of abnormal regional wall motion and myocardial infarct size in chronically infarcted dogs. Circulation 1977; 55-56, suppl III: III-271.

9 Meltzer RS, Woythaler JN, Buda AJ, et al. Non-invasive quantification of experimental canine myocardial infarct size using two-dimensional echocardiography. Eur $\mathcal{f}$ Cardiol 1980; 11: 215-25.

10 Wyatt HL, Meerbaum S, Heng MK, Rit J, Gueret P, Corday E. Experimental evaluation of the extent of myocardial dyssynergy and infarct size by twodimensional echocardiography. Circulation 1981; 63: 607-14.

11 Visser CA, Lie KI, Kan G, Meltzer R, Durrer D. Detec- 
tion and quantification of acute, isolated myocardial infarction by two-dimensional echocardiography. Am $\mathcal{J}$ Cardiol 1981; 47: 1020-5.

12 Heger JJ, Weyman AE, Wann LS, Rogers EW, Dillon JC, Feigenbaum H. Cross-sectional echocardiographic analysis of the extent of left ventricular asynergy in acute myocardial infarction. Circulation 1980; 61: 1113-8.

13 Weiss JL, Bulkley BH, Hutchins GM, Mason SJ. Twodimensional echocardiographic recognition of myocardial injury in man: comparison with postmortem studies. Circulation 1981; 63: 401-8.

14 Eaton LW, Weiss JL, Bulkley BH, Garrison JB, Weisfeldt ML. Regional cardiac dilatation after acute myocardial infarction. $N$ Engl f Med 1979; 300: 57-62.

15 Fiolet JWT, Willebrands AF, Lie KI, ter Welle HF. Determination of creatine kinase iso-enzyme MB (CKMB): comparison of methods and clinical evaluation. Clin Chim Acta 1977; 80: 23-35.

16 New York Heart Association (Harvey RM, chairman). Nomenclature and criteria for diagnosis of diseases of the heart and great vessels. 7th ed. Boston: Little Brown, 1973: 95-123.

17 Tajik AJ, Seward JB, Hagler JD, Mair DD, Lie JT. Two-dimensional real-time ultrasonic imaging of the heart and great vessels: technique, image orientation, structure identification amd validation. Mayo Clin Proc 1978; 53: 271-303.

18 Silverman NH, Schiller NB. Apex echocardiography: a two-dimensional technique for evaluating congenital heart disease. Circulation 1978; 57: 503-11.

19 Anderson RH, Becker AE. Cardiac anatomy. An integrated text and colour atlas. London: Gower Medical Publishing, 1980: 4.2-4.8.

20 Schiller NB, Acquatella H, Ports TA, et al. Left ventricular volume from paired biplane two-dimensional echocardiography. Circulation 1979; 60: 547-55.

21 Parisi AF, Moynihan PF, Foland ED, Strauss WE, Sharma GVRK, Sasahara AA. Echocardiography in acute and remote myocardial infarction. $\mathrm{Am}$ F Cardiol 1980; 46: 1205-14.

22 Corya BC, Rasmussen S, Knoebel SB, Feigenbaum H. Echocardiography in acute myocardial infarction. $A m \mathcal{F}$ Cardiol 1975; 36: 1-10.

23 Heikkilä J, Nieminen M. Echoventriculographic detection, localisation, and quantification of left ventricular asynergy in acute myocardial infarction. A correlative echo- and electrocardiographic study. Br Heart $\mathcal{F}$ 1975; 37: 46-59.
24 Myers GB, Klein HA, Hiratzka T. Part IV. Correlation of electrocardiographic and pathologic findings in infarction of the interventricular septum and right ventricle. Am Heart f 1949; 37: 720-70.

25 Savage RM, Wagner GS, Ideker RE, Podolsky SA, Hackel DB. Correlation of postmortem anatomic findings with electrocardiographic changes in patients with myocardial infarction: retrospective study of patients with typical anterior and posterior infarcts. Circulation 1977; 5: 279-85.

26 Carr KW, Engler RL, Forsythe JR, Johnson AD, Gosink B. Measurement of left ventricular ejection fraction by mechanical cross-sectional echocardiography. Circulation 1979; 59: 1196-206.

27 Silverman NH, Ports TA, Snider AR, Schiller NB, Carlsson E, Heilbron DC. Determination of left ventricular volume in children: echocardiographic and angiographic comparisons. Circulation 1980; 62: 548-57.

28 Hutchins GM, Bulkley BH, Ridolf RL, Griffith LSC, Lohr FT, Piasio MA. Correlation of coronary arteriograms and left ventriculogram with postmortem studies. Circulation 1977; 56: 32-7.

29 Wyatt HL, Forrester JS, DaLuz PL, Diamond GA, Chagrasulis R, Swan HJC. Functional abnormalities in nonoccluded regions of myocardium after experimental coronary occlusion. Am f Cardiol 1976; 37: 366-72.

30 Kerber RE, Marcus ML. Evaluation of regional myocardial function in ischemic heart disease by echocardiography. Prog Cardiovasc Dis 1978; 20: 441-50.

31 Myers GB, Klein HA, Hiratyka T. Part V. Correlation of electrocardiographic and pathologic findings in posterior infarction. Am Heart f 1949; 38: 547-92.

32 Durrer D, van Dam RT, Freud GE, Janse MJ, Meijler FL, Arzbaecher RC. Total excitation of the isolated human heart. Circulation 1970; 41: 899-912.

33 Morrison J, Coromilas J, Munsey D, et al. Correlation of radionuclide estimates of myocardial infarction size and release of creatine kinase-MB in man. Circulation 1980; 62: 277-87.

34 Heng MK, Lang TW, Toshimitsu T. Quantification of myocardial ischemic damage by two-dimensional echocardiography (abstract). Circulation 1977; 56, suppl III: III-125.

Requests for reprints to Dr C A Visser, Department of Cardiology and Clinical Physiology, Wilhelmina Gasthuis, Eerste Helmersstraat 104, 1054 EG Amsterdam, The Netherlands. 